\title{
For a Reappreciation of the Literary in Literary Studies: Poetic Thinking
}

\author{
MARKO PAJEVIĆ
}

\begin{abstract}
As a literary scholar based in German Studies outside of Germany, I am confronted with German being considered a minor subject matter. There are evidently clear differences between the German departments within German-speaking countries and abroad. The latter are shrinking considerably almost everywhere and need to focus on few aspects, often related to historical issues and some general successful movements, such as gender or postcolonialism. In Germany, there seems to be a preoccupation with didactics and media.

But since I consider these symptoms part of a wider issue, I prefer making some more general observations. World literature is - at least in the dominant anglophone cultures - increasingly identified with English language literature. Comparative literature programmes mostly work with translations as if those were original literary texts which - roughly speaking - reduces literature to its plot and, possibly, its structure. This is also reflected in the tendency in literary studies to be oblivious of the poetic approach.

Philologies are often subservient to outer goals (history, sociology, psycho$\operatorname{logy}$ ), and, in their efforts to justify their existence in the eyes of the market economy, they believe they cannot afford to deal with the core of what literature is about, the literary. In my view, this is one of the reasons for the difficulties of the philologies and possibly Humanities altogether. Literary studies, despite the various enriching overlaps with various other disciplines, should not forget this specificity, which I call poetics, the interaction of the form of language and the form of life. By making a strong case for the relevance of an understanding of what language is and does - and literature is the privileged field of observation - philologies would be of obvious importance for society as a whole.
\end{abstract}

Keywords: modern languages; German studies; world literature; comparative literature; Sprachdenken; life sciences; disciplines of meaning; poetics; poetic thinking; meaning-making processes

Allow me to first situate the position from where I am speaking: I am a literary scholar in the field of German studies, but after initial studies of Comparative Literature, Slavic studies and Philosophy in Germany I went to France to finish 
For a Reappreciation of the Literary in Literary Studies

my studies of Lettres Modernes there, with a $\mathrm{PhD}$ completed in collaboration in Paris and Berlin. I then worked in German studies in France, the UK and now, after a senior research fellowship in Berlin, in Tartu. I do research on German language authors but also more generally on what I call thinking language and poetics. That means that I am based in Modern Languages, German, with international experience, but I would rather consider myself to be a 'poetician', because my overarching research field is poetics in the sense of an interaction between the form of language and the form of life.

Working in German studies outside of the German speaking countries means that I am constantly confronted with the fact that German is not seen as a 'centric' culture anymore: departments are closing, students are lacking - it is a small discipline nowadays that has diminished by half in many places over the past 15 years. This is roughly the situation for most foreign philologies, apart from English. Things look different for literary studies in the form of the national philology - German philology in Germany has huge student numbers and in German language countries German studies (Germanistik) is still a 'centric' discipline - as well as in the form of Comparative Literature which seems to do much better than other philologies, recently often indeed at the expense of modern languages. This is the case at least in the UK, where a recent trend also sees huge successes for Translation studies and for Liberal Arts programmes, again at the expense of modern languages. It seems that students interested in literature and the Humanities prefer not to study Modern Languages. All of this is to say that my take on the situation of literary research is shaped by the minority position of Modern Languages.

My observations concerning German studies consequently have to take into consideration the situation within and without the German speaking countries. Apart from in very few countries, German as part of Modern Languages is in steep decline. Most departments struggle, with very few staff members and students to maintain a full curriculum. Particularly after Bologna everybody is frustrated that we have to let students graduate with a bare minimum of language skills and even less cultural knowledge. Language skills remain obviously the foundation of the field, whereas linguistics is rarely still taught or only in the few remaining large departments. Literature or 'philology' is only one small area within Modern Languages curricula nowadays, seen as one part of cultural studies, alongside film, history and general 'country studies' (Landeskunde), sometimes also visual arts. That means that many students have hardly any overview of literary history and their theoretical approach to literature really only starts once they have decided to focus on that field as postgraduates. Few students in Modern Languages have an urgent desire 
PAJEVIĆ

to deal in depth with literature. Literary studies in Modern Languages are condemned to take the form of scarce patchwork.

There are, however, still a lot of colleagues who specialized in literature. They often feel compelled to take a historic angle on literature since this is considered useful for the students. Theory is less valued. In France, new posts are most often filled with linguists since they are deemed more suitable to teach language or so-called applied foreign languages (langues étrangères appliquées = LEA). For this also historians are in demand, in my view a completely wrong strategy for small departments since the cultural approach gets neglected and the students acquire little knowledge about their specialty culture which makes it hardly possible to sufficiently analyse and interpret its phenomena. In the UK, literary colleagues still have a chance on the job market, but there are obviously some fields en vogue, such as gender or postcolonial studies, the latter still being quite a recent development in German studies.

In Germany, it is remarkable that almost all advertised posts are profiled on didactics, or at least didactics combined with other aspects such as literature. I have not seen a post for poetics for many years, nowhere. Decision makers seem to believe that a new generation of Germanists all specialized in didactics will indeed enable young people to get more out of literature - you are noticing that I am sceptical.

Digital Humanities are obviously also much in demand. It seems to me, however, that this label is mostly used for establishing digital editions, very few research projects to my knowledge really deal with the wider and deeper effects of our digital age and analyse how to deal with the involved challenges and consequences for society and human life.

Literature is not in crisis, from what I can see, the book market still booms, in Germany at least there are lots of quite successful literature TV-shows, literary festivals attract large audiences, reading circles are quite fashionable nobody puts in question the value of literature. The value of literary studies, however, possesses less esteem in the public eye, it seems. So, there is a need for making understandable the use of studying literature and literary theory. The general public sees the interest of literature - if not plainly in entertainment mostly in historic terms: literature gives us knowledge about the past. That is true and precious, but that is certainly far from being exhaustive. For this reason, in this paper I would like to stress another crucial aspect and outline how I see the philologies, what they should do and why society has to change its ideas about what philologies, and more precisely literature, is and does. 
Before, however, as a preparation for the following, just another quick word concerning a debate in Comparative Literature, illustrating the problem I want to point at: in the Anglophone world particularly, there has been for some time now a very vivid discussion about the notion of world literature, and it seems that many people believe in world literature being necessarily in English. It is also remarkable that comparatists in these countries seem to read exclusively in English, at least at more and more universities the curricula do not necessitate any other language skills. That means you can officially 'compare' literatures without being able to read any literature outside of the one written in English. So, what do they compare? I say this a little provocatively, of course, but reading in translation means reading for the plot, the literary aspect is not considered in such programmes, since they pretend that there is no translation; the translation is not analysed, cannot be analysed without foreign language skills. That means, there is no language in that approach to literature. Literature is reduced to stories at the universities organizing their literary studies this way. No need to say that almost exclusively novels are on the curricula. I believe there is still a lot of good in these studies and one can indeed study literature this way with a lot of profit in various ways and aspects, however, the specifically literary aspect does not play a major role. And to me that seems telling for the problems I see with literary studies today and indeed with society generally. This is the point where I would like to tackle the issue from a poetic perspective.

For me, following Henri Meschonnic (for example 1995 and 2019), poetics means first and foremost the interaction between the form of language and the form of life. There is a particular German tradition of 'thinking language', Sprachdenken, starting with Leibniz. Almost the entire philosophical history considers language to be either pure communication (this is the Aristotelian tradition) or, with the words of Locke, as 'a mist before our eyes' (Locke 1690) (an ongoing tradition starting with Plato), that is, as an obstacle to clear rational thinking. Against all of this Leibniz called language the 'best mirror of our mind', manifesting 'the wonderful variety of the operations of the human mind' (Leibniz 1765: 290/293). This tradition continued with Hamann, Herder and reached its peak with Wilhelm von Humboldt (cf. Trabant 2003). The entire German Romantic movement very much built on it. This tradition considers language to be not only a tool for, but actually the organ of, thought - that is why Sprachdenken is an appropriate term for it. Without language, consequently, there cannot be thought, humanity, society. Meschonnic's above definition of poetics, as interaction between the form of language and the form 
PAJEVIĆ

of life, means exactly this. Poetics then would be both, that what happens in this interaction and its analysis.

This is evidently an enormous claim, covering and concerning the entire epistemology. Poetics is of fundamental relevance for any field, because no matter what one analyses, there is always thinking involved and thinking takes place in language; hence, understanding how language functions touches at any thought processes. Literature then is a privileged field for the study of these processes, since literature would be the form of language that is the most aware of its form and where this interaction takes place to a maximum. Meschonnic therefore calls literature 'a maximum subjectivation'. Linguistically speaking, with Émile Benveniste (1966), one is always subject by saying 'I'. Poetically speaking, when the form of language acts on the form of life and vice versa, literature is speech in which one speaks most subjectively and creatively, therefore, during this activity, one becomes subject to the highest degree. If we agree with Leibniz that language is the mirror of our mind, then the study of literature enables us best to study the functioning of our mind. Poetics in this understanding is therefore a form of cognitive science.

There is also an ethical aspect in all of this. Meschonnic wrote 'Est sujet par qui un autre est sujet.' (Meschonnic 2008: 42) (Subject is through whom someone else is a subject). This is based in the dialogical condition of language and of humankind generally: saying 'I' immediately implies a reference to a you. This you, however, is different from a he, she or it, it is not an object but also a subject. ${ }^{1}$ There is no I without a you, there is no subjectivity without the presupposition of another subjectivity. An awareness of our dialogical condition is ethically relevant.

The specificity of literary studies is then the most developed understanding of this sort of subjectivity shaped in language, and that means not only what is said in language, but it means the language form: how something is said. The form is semantic, it is meaningful. Literary studies, dealing with the form of language and the constitution of subjectivity and meaning in this language form, and how these forms of language interact with the forms of life, is crucial for understanding the constitution and processes of meaning.

Unfortunately, the term life sciences has already been taken by the natural sciences, but this implies a terrible reduction of life to biological or chemical processes, to life as pure life (zö̈) instead of as a form of life (bios) (cf. Agamben

Wilhelm von Humboldt first formulated this linguistic dialogism (1913); Benveniste elaborated on it (1966); Martin Buber developed an entire philosophy around this dialogical principle (1923). 
1998). The label life sciences would be much better suited for literature and the humanities generally; they are the fields where the human is at stake, here we negotiate more than anywhere else what life is and means (cf. Pajević 2012, particularly 35-48).

- A quick observation aside: when people say that education should make young people learn for life, they refer mostly to law or business studies. But actually, what they mean is not learning for life but learning for the job market. That is a poor definition of life. There is no better way of learning for life than reading a poem, for instance, or dealing with the arts generally. -

Consequently, it is in the humanities that we interpret the phenomena of life. And the interpretation of these phenomena is what makes them what they are in the human world. Through language we give meaning to them; without language and a discourse around them, they do not mean anything yet. Language is actually our access to reality; we do not have any other. There is a difference between facts and what one does with them. There are no facts without interpretation. They need to be put in context, in historically and culturally determined worldviews. Our sensations - physicality - are always in need of language and interpretation and the same phenomena can and are interpreted very differently by different cultures, times and individuals. The humanities are thus in charge of human life. But the power constellation is such that putting up a fight for claiming the term life sciences for the humanities would be a lost battle from the start.

What we in the humanities could do, however, particularly in literary studies, is to establish the term disciplines of meaning or research on meaning, since we are in charge of the meaning of things, or at least in charge of understanding how meaning-processes take place. That would then also establish the social relevance and importance that our times seem to dispute and deny the humanities, and even more so literary studies.

Considering biology, neurosciences or any other so-called hard science as guiding discipline implies a denial of the constitutional historicity of meaning. We need academic disciplines which analyse the meaning-making processes. Disciplines which analyse how we translate our sensual perceptions into meaning and into a worldview, to use again Humboldt's famous term for languages, that is, into a way how we see the world - our world, because we can never have any other but our historically determined world, constantly subject to change due to our way of talking and thinking about it, in community with other human beings.

Literature cultivates a knowledge of life forms, and it also projects, drafts and designs new life forms. By doing so, it plays an important role in 
PAJEVIĆ

transforming and adapting human life to new life situations - that is crucial for our survival, more than ever, since our environment, mostly due to technological developments, changes rapidly and without humans developing new thinking and new forms of life, we will not be able to meet these new challenges. We have to make sense of these changes.

But beyond this sociological relevance of literature I would like to stress once more that literature does much more than presenting us with new life designs and interpretations. It is even more so the poetic in literature where meaning constitutes itself. The best laboratory for these processes is actually poetry. In poetry and the study of poetry, we can develop best an awareness of what language is and does. And from my point of view, it is no coincidence that poetry is little studied these days - literary departments by far prefer prose. Again, I have no problems with all other possible fields, what I am denouncing is a lack - a lack of poetics that is telling for a general oblivion of the specificity of literature and of the relevance of this specificity for the political. By the political, I mean the common space of human life and the relations within this space. As already explained, language is what determines all our relations, including the one with ourselves.

Poetics has been presented as research on meaning. Consequently, any research field that goes beyond 'facts' is connected to poetics. Literary studies keeping in mind poetics could be at the forefront of the transformative force that I call poetic thinking, that is, a thinking mindful of poetics, of Sprachdenken, the fact that our thinking is necessarily in language and constitutes our world, and of our dialogical condition as dyadic beings, always only conceivable starting from our relationship to a you. My definition of poetic thinking is consequently as follows: it is the transforming power in the interaction of the form of life and the form of language that acts when a subject constitutes itself in a creative and dialogical way, transforming the ways we feel, think, understand, in short: the way we perceive the world (Pajević 2012: 13).

I am pleading consequently for taking into account and teaching the meaning making power of literature in literary studies. If we succeed to do this, we are at the same time empowering the non-centric smaller literatures, since attention to language means attention to languages, to all of them. The wonderful variety of the operations of the human mind, that Leibniz praised means that the more languages we take into consideration, the more variety we have, the richer our grasp of the world, the fuller our vision of humanity. Literary studies, as the study of meaning in language forms, is key to what we have understood as humanity so far - we should not give this up if we do not want to give up on the human. 
For a Reappreciation of the Literary in Literary Studies

\author{
Marko Pajević \\ Marko.pajevic@ut.ee \\ Tartu Ülikool \\ Maailma keelte ja kultuuride kolledž \\ Lossi 3 \\ 51003 Tartu
}

EESTI / ESTONIA

\title{
References
}

Agamben, G. 1998. Homo Sacer: Sovereign Power and Bare Life. Stanford: Stanford University Press.

Benveniste, É. 1966. De la subjectivité dans le langage. - Problèmes de linguistique générale. Paris: Gallimard, 258-266.

Buber, M. 1962 [1923]. Ich und Du. - Werke in drei Bänden. München/ Heidelberg: Kösel/ Lambert Schneider, I/77-170.

Humboldt, W. von. 1907 [1827]. Ueber den Dualis. - Gesammelte Schriften IV. Edited by A. Leitzmann. Berlin: Behr, 4-30.

Leibniz, G.W. 1966 [1765]. Nouveaux essays sur l'entendement humain. Edited by J. Brunschwig. Paris: Garnier-Flammarion.

Locke, J. 1971-4 [1690]. An Essay Concerning Human Understanding, 2 Vol. Edited by J.W. Yolton. London/ New York: Dent/Dutton.

Meschonnic, H. 1995. Politique du rythme, politique du sujet. Lagrasse: Verdier.

Meschonnic, H. 2008. Dans le bois de la langue. Paris: Laurence Teper.

Meschonnic, H. 2019. The Meschonnic Reader. A Poetics of Society. Edited by M. Pajević. Edinburgh: Edinburgh University Press.

Pajević, M. 2012. Poetisches Denken und die Frage nach dem Menschen. Grundzüge einer poetologischen Anthropologie. Freiburg im Breisgau: Karl Alber.

Trabant, J. 2003. Mithridates im Paradies. Kleine Geschichte des Sprachdenkens. München: C.H. Beck. 